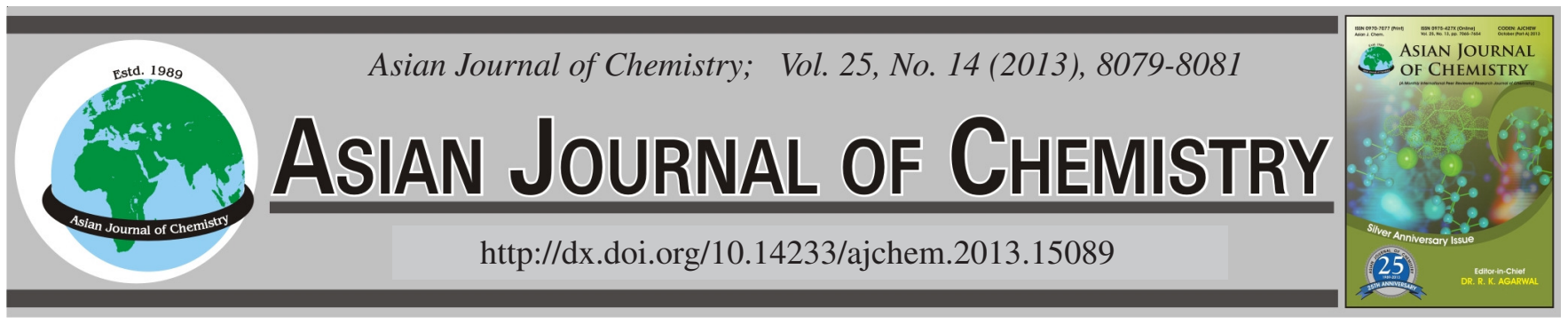

\title{
Effects of the Different Methacrylate Monomers on Bond Strength Between Soft Liner and Acrylic Resin
}

Giray Bolayir $^{1, *}$, Koray Soygun $^{1}$, Selçuk SimseK $^{2},{\text { Ersen } \text { Yilmaz }^{2}, \text { Arife Dogan }^{3}, \text { Ali Boztug }}^{4}$ and Orhan Murat Dogan $^{1}$

${ }^{1}$ Department of Prosthodontics, Faculty of Dentistry, Cumhuriyet University, Sivas, Turkey

${ }^{2}$ Department of Chemistry, Cumhuriyet University, Sivas, Turkey

${ }^{3}$ Department of Prosthodontics, Faculty of Dentistry, Gazi University, Ankara, Turkey

${ }^{4}$ Department of Chemistry, Tunceli University, Tunceli, Turkey

*Corresponding author: Tel: +90 346 2191010-2783; E-mail: giraybolayir@ hotmail.com

\begin{abstract}
In the present study, tensile bond strength between on acrylic resin and a soft liner, molloplast B, was studied. To enhance the bonding capacity between these materials, acrylic resin surface was modified using ethyl methacrylate, iso-butyl methacrylate or tert-butyl methacrylate monomers. The monomers were applied onto the surfaces of methacrylate components for 60,120 or $180 \mathrm{~s}$ and the bond strength values were obtained. The values were statistically compared. Changes on the modified surfaces were investigated by fourier transform infared spectroscopy with attenuated total reflectance (FTIR-ATR). The highest bond strength value was obtained from $120 \mathrm{~s}$ treatments with ethyl methacrylate and the lowest value was obtained from $60 \mathrm{~s}$ treatments with iso-butyl methacrylate. These high alkyl monomers also had secondary interactions on the acrylic surfaces, evidenced by FTIR-ATR.
\end{abstract}

Key Words: Acrylic resin, Soft liner, Bond strength, Surface treatment, FTIR-ATR.

\section{INTRODUCTION}

The use of soft liner materials may be advantageous for patients who are capable of delivering a relatively heavy occlusal load to unfovorable denture-bearing tissues. These materials improve the intaglio denture surface and retention of the prosthesis ${ }^{1-5}$. There are some disadvantages in the use of soft liner materials, including various degrees of softness or poor bond strength. One important problem with silicon based soft liners is the failure of adhesion between the soft liner and acrylic resin ${ }^{6-8}$. To improve bonding between them, researchers have tried to alter the acrylic resin surface before applying a soft liner material ${ }^{9-13}$. It has been proposed that roughening of the surface of acrylic resin by laser treatment had a positive influence on its bonding with soft-liner material $^{14}$. Furthermore, it has also been reported that modification of the resin surface by using different chemical agents increased its bonding strength to methyl methacrylate, methylene chloride or acetone ${ }^{15}$.

Many researchers have measured the bond strength between the soft liner and acrylic resin materials by using peel, shear and tensile bond tests. It has been shown that the measured bond strength of soft liners to acrylic is often dependent on the type of testing method used. The tensile bond strength test is a good method in investigating the bond strength of soft liner materials ${ }^{16-19}$.

In a previous study we have studied the effects of isobutyl methacrylate and tert-butyl methacrylate monomers on the bonding strength between silicone-based liner material and acrylic resin ${ }^{20}$. It has been evidenced that different application time periods $(5,15$ or $30 \mathrm{~s})$ of the monomers resulted in different bond strengths. In the present study the same monomers were used with longer application times (60, 120 and $180 \mathrm{~s})$ in order to obtain a more complete picture for the effect of the duration of monomer application on the bonding strength of silicone based liner materials to acrylic resin. Changes on the resin surface caused by the applied monomers were determined by using fourier transform infrared spectrometer attenuated total reflectance (FITR-ATR).

\section{EXPERIMENTAL}

The resilient liner used in this study was a silicon-based relining material (Molloplast-B, Detax, Ettlingen, Germany), the Primo adhesive (Molloplast-B, Detax, Ettlingen, Germany) and the denture base material was a heat-cured polymerized acrylic resin (Meliodent, Bayer Dental, Newbury, UK). The surface of acrylic resin was wetted using ethyl methacrylate, 
iso-butyl methacrylate or tert-butyl methacrylate monomers (Acros, Belgium).

For testing of the tensile bond strength, acrylic specimens of $75 \mathrm{~mm}$ in length and 12 and $7 \mathrm{~mm}$ in diameter (wide and narrow areas, respectively) were prepared. Three milimeter sections were cut out from the narrow midsection of specimens using a water cooled saw (model No. 11-1280-250, Buhler Ltd, Lake Bluff, IL, USA) in order to obtain spaces for resilient liner placement. These specimens were stored in distilled water for $24 \mathrm{~h}$ before the surface pretreatment. The samples were divided into three main groups on the basis of the solvent with which the surfaces were to be treated and each of these groups were divided into three subgroups on the basis of the treatment times used. In this study ten groups, including the control, were used and each of the groups contained ten samples. All specimens (except for the samples of control group) were treated by immersion of the plate inner surfaces into different chemical materials. The duration of immersion in ethyl methacrylate, iso-butyl methacrylate or tert-butyl methacrylate was 60,120 or $180 \mathrm{~s}$. Specimens of control group were not treated. All specimens were left to dry for 2 min after pretreatment. The primo adhesive of silicon resilient liner was applied to the treated surfaces with a brush and allowed to dry for $1 \mathrm{~h}$. Resilient liner material was then packed in the spaces created before and processed for $2 \mathrm{~h}$ in a boiling water bath. The processed flasks were left to cool at room temperature for $20 \mathrm{~min}$ and were kept under the tap water for $10 \mathrm{~min}$.

The tensile bond strength of the specimens was measured on a universal testing machine (Lloyd NK 5, Lloyd Instruments Ltd., Fareham, Hampshire, UK) using a crosshead speed of $50 \mathrm{~mm} / \mathrm{min}$. Tensile bond strength was calculated using the formula:

$$
\mathrm{S}(\mathrm{MPa})=\frac{\mathrm{F}}{\mathrm{D}}
$$

where $\mathrm{S}$ is tensile bond strength (MPa), $\mathrm{F}$ is the force $(\mathrm{N})$ and $\mathrm{D}$ is the adhesion surface area $\left(\mathrm{mm}^{2}\right)$.

Bond strength values were analyzed by Kruskall-Wallis and Mann-Whitney U test using on SPSS (version 14.0, SPSS Inc. Chicago, USA) programme.

\section{RESULTS AND DISCUSSION}

Data obtained from the testing experiments were shown in Table-1. Differences in the bonding strengths of ethyl methacrylate, iso-butyl methacrylate and tert-butyl methacrylate groups prepared using the same application time period were not statistically significant when compared within themselves $(p>0.05)$.

Values obtained from the applications of ethyl methacrylate, iso-butyl methacrylate, tert-butyl methacrylate and control groups were also compared. Pair wise comparison of the groups prepared using sixty seconds application time period indicated significant differences between the groups $(p<0.05)$ other than control and ethyl methacrylate and iso-butyl methacrylate and tert-butyl methacrylate.

Bond strength values obtained from the groups of $120 \mathrm{~s}$ of application indicated statistically significant differences between ethyl methacrylate and iso-butyl methacrylate and ethyl methacrylate and tert-butyl methacrylate groups $(p<0.05)$

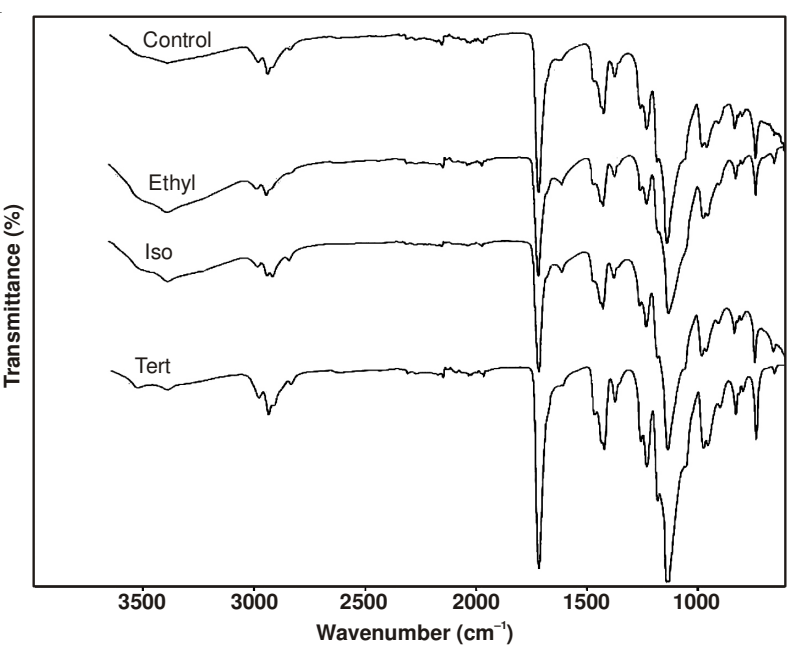

Fig. 1. FTIR-ATR spectra of groups treated for $60 \mathrm{~s}$

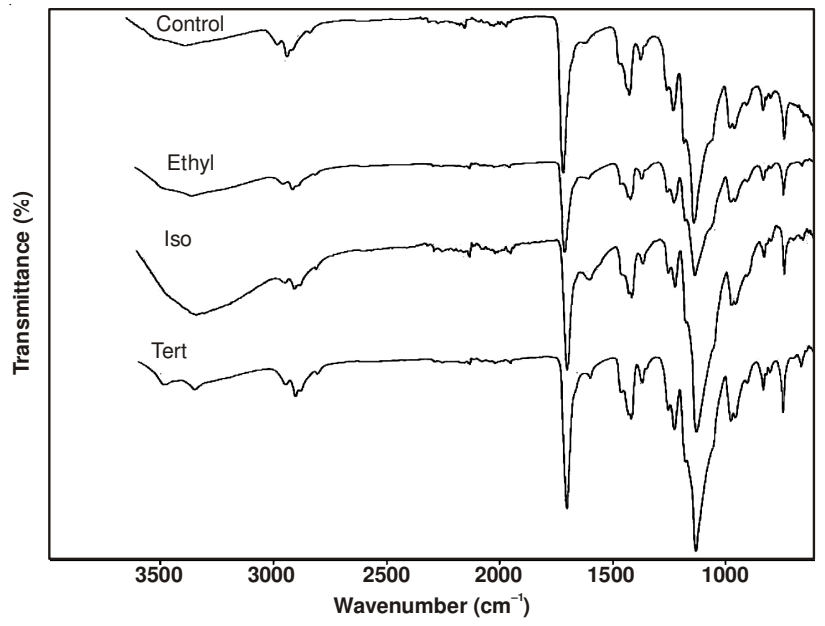

Fig. 2 FTIR-ATR spectra of groups treated for $120 \mathrm{~s}$

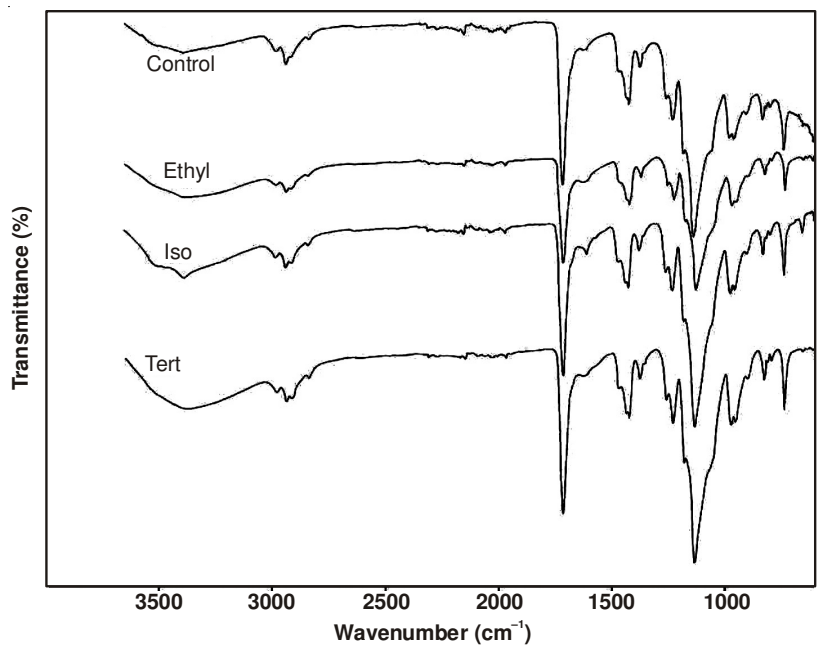

Fig. 3. FTIR-ATR spectra of groups treated for $180 \mathrm{~s}$

when compared to the values of the respective control specimens. The treatment for $180 \mathrm{~s}$ of treatment did not cause any significant difference in the strength of bonding $(p>0.05)$.

FTIR-ATR is an important method for the determination of secondary interactions occurring between side groups as well as understanding molecular structures. In the IR spectra, all of the specimens produced broad peaks (between 17201640 ) for the carbonyl groups and sharp peaks for the C-H 
TABLE-1

MEAN VALUES AND STANDARD DEVIATIONS OF TENSILE BOND STRENGTH (MPa)

\begin{tabular}{|c|c|c|c|c|c|}
\hline \multirow{2}{*}{ Groups } & \multicolumn{5}{|c|}{ Applications times } \\
\hline & $60 \mathrm{~s} \mathrm{X} \pm \mathrm{SD}$ & $120 \mathrm{~s} \mathrm{X} \pm \mathrm{SD}$ & $180 \mathrm{~s} \mathrm{X} \pm \mathrm{SD}$ & & \\
\hline Control & $1.63 \pm 0.52^{\mathrm{a}, \mathrm{b}}$ & $1.63 \pm 0.52$ & $1.63 \pm 0.52$ & $p=0.075$ & $p>0.05$ \\
\hline Ethyl methacrylate & $1.59 \pm 0.26^{\mathrm{c}, \mathrm{d}}$ & $1.96 \pm 0.25^{\mathrm{eff}}$ & $1.61 \pm 0.18$ & $p=0.386$ & $p>0.05$ \\
\hline iso-Butyl methacrylate & $1.02 \pm 0.28^{\mathrm{a}, \mathrm{c}}$ & $1.27 \pm 0.23^{\mathrm{e}}$ & $1.23 \pm 0.39$ & $p=0.651$ & $p>0.05$ \\
\hline \multirow[t]{3}{*}{ tert-Butyl methacrylate } & $1.14 \pm 0.18^{\mathrm{b}, \mathrm{d}}$ & $1.27 \pm 0.21^{\mathrm{f}}$ & $1.29 \pm 0.37$ & & \\
\hline & $\mathrm{KW}=10.86$ & $\mathrm{KW}=8.50$ & $\mathrm{KW}=6.28$ & & \\
\hline & $p=0.012$ & $p=0.037$ & $p=0.099$ & & \\
\hline
\end{tabular}

stretching (between 2950-2850) (Figs. 1-3). It can easily be seen that carbonyl groups of the control specimen drifted towards lower wave numbers after interacting with methacrylate. The drift appeared to be more prominent in $120 \mathrm{~s}$ application of ethyl methacrylate. FITR- ATR indicated that hydrogen bonds were formed between control sample and methacrylate. By inspecting the drift of control carbonyl group this hydrogen bonding seemed to be stronger between control and ethyl methacrylate group.

Researchers have been performed to increase bonding strength between the liner material and acrylic resin ${ }^{21,22}$. Acrylic resin surfaces has been modified with maleic anhydride, styrene, vinyl actetate or its ester derivatives and the strongest bond strength has been found from the applications of $n$ butylmaleate-styrene-vinyl acetate $(2.11 \pm 0.21 \mathrm{MPa})^{10}$. In another study acrylic resin surfaces have been conditioned by treatments with different chemical agents and the strongest bond strength has been recorded for the methyl methacrylate treated specimens $(2.22 \pm 0.04 \mathrm{MPa})$. This value is higher than the highest bond strength value registered for the $120 \mathrm{~s}$ application in the present study. This could be accounted for by the structural differences in the chemical agents used. The highest bond strength value obtained from the ethyl methacrylate application could result from the lesser degree of steric hindrance existing in this agent. This finding also suggests that longer application times had a positive influence on the bonding properties of ethyl methacrylate. Longer application time periods appear to negatively influence some of the agents. For example, longer applications of iso-butyl methacrylate decreased the bonding strength of the specimens. These results could imply that the effects of monomers with high alkyl contents could change with the duration of the surface conditioning.

To sum up, in the lights of the results of mechanical tests and FTIT-ATR, it might be argued that the changes could arise because of the modification of acrylic surfaces by the applied monomers which influence the bonding strength between the liner and acrylic surface.

\section{REFERENCES}

1. S. Pavan, J.N.A. Filho, P.H. Dos Santos, S.S. Nogueira and A.U. Batista, J. Prosthodont., 20, 101 (2007)

2. M. Barden, P.S. Wright and S. Parker, Eur. J. Prosthodont. Rest. Dent., 3, 163 (1995).

3. F. Kawano, A. Koran, A. Nuryanti and S. Inoue, Int. J. Prosthodont., 10, 55 (1997)

4. S. Qudah, A. Harrison and R. Huggett, Int. J. Prosthodont., 3, 477 (1990).

5. H. Nikawa, H. Iwanaga, T. Hamada and S. Yuhta, J. Prosthet. Dent., 72, 657 (1994).

6. F. Kawano, E.R. Dootz, A. Koran and R.G. Craig, J. Prosthet. Dent., 68, 368 (1992).

7. D. Sinobad, W.M. Murphy, R. Huggett and S. Brooks, J. Oral Rehabil., 19, 151 (1992).

8. J.C. Davenport, H.J. Wilson and R.M. Basker, J. Dent., 6, 239 (1978).

9. O.M. Doðan, S. Keskin, G. Bolayir, A. Usanmaz and B. Bek, J. Adhesion, 83, 129 (2007).

10. O.M. Dogan, G. Bolayir, A. Boztug, M. Turgut and H.B. Zengin, J. Appl. Polym. Sci., 104, 1338 (2007).

11. W.M. Amin, A.M. Fletcher and G.M. Ritcihie, J. Dent., 9, 336 (1981).

12. N.L. Jacoobsen, D.L. Mitchell, D.L. Johnson and R.A. Holt, J. Prosthet. Dent., 78, 153 (1997).

13. R.G. Jagger, M.S. Al-Athel, D.C. Jagger and R.W. Voies, Int. J. Prosthodont., 15, 55 (2002).

14. G. Bolayir, M. Turgut, Ý. Hubbezoglu, O.M. Doðan, S. Keskin, A. Dogan and B. Bek, J. Adhesion, 83, 117 (2007).

15. Y.S. Sarac, T. Basoglu, G.K. Ceylan, D. Sarac and O. Yapici, J. Prosthet. Dent., 92, 283 (2004).

16. P.N. Economou, T.E. Fsicher, J. Lemons and D.J. Castleberry, J. Prosthet. Dent., 44, 604 (1980).

17. C.A. Arena, D.B. Evans and T.J. Hilton, J. Prosthet. Dent., 70, 126 (1993).

18. J. Bunch, G.H. Johnson and J.S.J. Brunvink, Prosthet. Dent., 57, 512 (1987).

19. A. Bolouri, A.V. Marker and R. Sarampote, J. Dent. Res., 68, 337 (1989).

20. G. Bolayir, H. Demir, A. Dogan, A. Boztug, O.M. Dogan and K. Soygun, Mater. Res. Innov., 13, 431 (2009).

21. M. Turgut, G. Bolayir, O.M. Dogan, S. Keskin, A. Dogan and A. Boztug, J. Adhesion, 83, 927 (2007).

22. W.E. Wood, D.L. Johnson, M.G. Duncanson, J. Prosthodont., 2, 13 (1993). 